\title{
THE MATRIX: \\ A AVENTURA DA FORMAÇÃO NO MUNDO TECNOLOGIZADO
}

\author{
Flávio Caetano da Silva*
}

\begin{abstract}
RESUMO: $\mathrm{O}$ artigo se inscreve na intersecção entre a educação e a produção fílmica. $\mathrm{O}$ argumento propõe reflexões sobre a educação escolar e as formas de controle exercido no cotidiano de alunos, professores e gestores a partir de instigantes provocações que o filme The Matrix, o primeiro da trilogia, nos oferece. Nosso interesse está nas práticas escolares de institucionalização dos sujeitos, produzindo realidades inevitáveis. Os sujeitos são produzidos através de discursos sofisticados, mediados pelas novas tecnologias de comunicação e informação. Nos propomos a discutir tanto as formas de controle do pensamento e de sua produção, quanto a própria possibilidade de realizar percursos no interior do roteiro de um filme, considerando as tramas de seu enredo. Estabelecemos uma leitura exploratória da construção do herói dostoievskiano para superar uma leitura superficial e fatalista, possível naquele filme.

Palavras-chave: Realidade-irrealidade. Controle. Formação do "Eu". Educação. Matrix.
\end{abstract}

THE MATRIX: THE FORMATION ADVENTURE IN A TECHNOLOGIZED WORLD

ABSTRACT: This article is in the intersection between education and movie production. The argument suggests reflections about school education and the forms of control that it has over students', teachers' and directors' everyday lives, with the use of great instigation provided by The Matrix, the first movie of the Matrix trilogy. Our focus in on school practices towards institutionalizing individuals, creating inevitable realities. Individuals or subjects are produced

* Doutor em Educação, professor de Filosofia da Faculdade de Americana (FAM) e professor susbtituto do Departamento de Educação da Universidade Federal de São Carlos (UfSCAR). E-mail: flaviocaetano@fam.br/flaviorosi@terra.com.br 
by means of sophisticated discourse which is mediated by communication and information technologies. We wish to discuss the ways of controlling human thought and its production, as well as the possibility to take paths inside a movie script, considering the meanderings of its plot. An exploratory look on the construction of Dostoievsky's hero is established to outdo an eventually superficial and fatalistic look on the movie.

Key words: Reality-(ir)reality. Control. Building the "Self". Education. The Matrix.

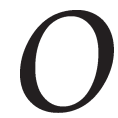

uso de filmes pode significar um importante recurso no trabalho pedagógico que realizamos. Porém, algumas reflexões são necessárias para que possamos aprofundar os saberes que julgamos necessários para um bom uso desse recurso. No presente texto, nos propomos a oferecer uma reflexão em torno de um filme específico - The Matrix (1999) - através do uso de recursos do paradigma indiciário (Ginzburg, 1999) e de conceituaçōes filosóficas que, pensadas para o campo da educação, nos forneçam respostas plausíveis a uma pergunta que há tempos nos incomoda: Como compreender o processo de formação no qual estamos envolvidos permanentemente?

Realizar a busca que nos permita chegar a essa compreensão supõe determinadas escolhas. Escolhas são oferecidas a nós mediante certas possibilidades e estas estão inseridas em dadas circunstâncias. Portanto, ao nos perguntarmos sobre o processo de formação que nos envolve, desejamos saber como se dão as escolhas e mediante quais circunstâncias podemos nos propor semelhante pergunta. Nossa opção material para realizar tal busca é a produção fílmica. O cinema nos oferece instigantes vantagens para realização de leituras e aprendizagens em torno de temas que consentimos urgentes e fundadores de novas formas de vivência e trabalho. Somos o que produzimos e produzimos o que somos, certamente no conjunto das relações sociais e das configuraçôes políticas nas quais estamos imersos. O cinema póe em evidência, como discurso e possibilidade, novas formas de chegar a ser o que somos.

O recurso audiovisual é "lugar-comum" ao percebermos que muitas escolas apresentam o par vídeo-tevê como equipamentos obrigatórios a serem oferecidos aos professores para que dinamizem suas aulas. Esse fenômeno pode ser decorrente do interesse pela qualidade das 
aulas e do ensino que se oferece, nesses tempos em que a tecnologia se articula como um dos eixos mais visíveis nas práticas discursivas da atualidade. Mas pode também ser outra coisa. Talvez isso ocorra por força de um neotecnicismo prático engendrado no bojo das lutas entre os defensores das técnicas como panacéia para os problemas educacionais, a partir dos anos de 1970 mais visivelmente, e aqueles que buscam novas possibilidades de leitura do mundo que nos cerca. A questão que surge nesse horizonte teórico refere-se à "tecnologia educacional". No entanto, devemos perguntar: Há um consenso sobre o que venha a ser isso? No âmbito do presente texto, não nos dedicaremos a esse tema como eixo central, embora ele esteja rondando, sub-repticiamente, a enunciação que aqui se efetiva.

Dissemos que a materialidade que nos convoca para a presente reflexão é o filme. Trata-se de dizer, em verdade, que a relação homemmáquina está em jogo no palco das enunciações que aqui se estabelecem, uma vez que ela própria estará em cena. Nesse sentido, nos alinhamos com os dizeres de Pretto (2000), para quem é preciso que estejamos dispostos a refletir, não apenas nas inovações tecnológicas que a sociedade atual coloca ao nosso dispor; nem, tampouco, apenas nas formas de uso que damos a elas no espaço educacional. Mas é urgente atentarmos para a "relação do ser humano com as máquinas". Citando Santaella, Pretto (ibid.) nos adverte que grandes transformações estão ocorrendo debaixo do nosso nariz a despeito de nos darmos conta. Trata-se de uma revolução silenciosa que se opera no interior de outra bastante ruidosa, aquela relativa à emergência de uma nova humanidade e esta relativa à revolução tecnológica que vivemos sem precedentes. Kuenzer (2000) também assinala que essas transformações que vêm ocorrendo geram uma mudança profunda:

A partir das novas tecnologias de base microeletrônica, portanto, muda o eixo da relação entre homem e tecnologia, que agora passa a se dar com os processos, e não mais com os produtos. Desta forma, a substituição da rigidez pela flexibilidade significa que, pelo domínio dos processos, as possibilidades de uso das tecnologias não mais se limitam pela ciência materializada no produto, mas dependem do conhecimento presente no produtor ou usuário. (Kuenzer, 2000, p. 141; grifos da autora)

A tão buscada "inteligência artificial" parece ofuscar em vez de revelar uma outra busca, um outro desejo das sociedades modernas: a 
realidade artificial. Ou, porque não dizer, a sociedade artificial, também chamada por muitos de "realidade virtual", que poderia denominar de potencial e que certamente faria Aristóteles arregalar os olhos, uma vez que o seu devir poderia estar não apenas contido no ser, mas realizar uma outra forma do próprio ser; abrindo a possibilidade daquilo que, sendo algo que possa existir simultaneamente enquanto é outra coisa, porém já não mais escamoteada na distinção entre potência e ato. Essa possibilidade invoca o continuum entre o gerúndio "sendo" e o presente "é", numa nova forma de concepção não apenas do ethos, do ser sujeito neste mundo, mas sobretudo do cronos, do tempo em que vivemos, pois instala-se uma contenda entre o que se é e o que se deseja ser, mediada pelo próprio tempo que a tudo devora. ${ }^{1}$

Assim, vislumbramos a possibilidade de nos determos por um momento e refletirmos sobre uma leitura da formação escolar a partir de um filme que organiza seu roteiro na relação entre o homem e a máquina, oferecendo uma leitura futurista, na qual, após a eclosão de uma guerra entre ambos, as máquinas teriam submetido a humanidade. Trata-se do filme The Matrix, dos irmãos Larry e Andy Wachowski, que arrastou multidões aos cinemas pelo mundo todo, já tendo sido apresentado sob a promessa de uma "trilogia": o primeiro filme foi lançado em 1999, o segundo em maio de 2003 e o terceiro previsto para novembro do mesmo ano - e efetivamente lançado naquele momento (The Matrix Reloaded e The Matrix Revolutions, respectivamente segundo e terceiro filmes).

Não pretendemos aqui realizar uma ampla discussão sobre o filme, seu roteiro, sua banda visual ou sua banda sonora. Cada uma dessas três partes conta uma história particular na película, como, aliás, acontece em todos os filmes que possuem sons, imagens e texto. Mas ensejamos levantar algumas metáforas no campo pedagógico que são provocadas pelo primeiro filme da série. Propomos-nos nesse artigo realizar uma leitura de algumas das relações de poder que são vivenciadas no interior da instituição escolar, a partir de contribuições de Foucault (1996, 1997, 1998 e 1999), e estabelecer um diálogo baseado em uma breve incursão pela tênue divisa entre o mundo da realidade e da irrealidade na escola.

Uma incursão é também uma viagem como aquela realizada por Alice em direção à toca do coelho e ao seu interior, no conto infantil de Lewis Carroll $^{2}$ intitulado Alice no pais das maravilhas, publicado originalmente em 1865. Dessa toca, nunca mais a pequena Alice sairia a mesma. 
Nossa proposta é realizar uma viagem pelo interior da "toca do coelho" que denominamos Escola. Essa viagem é um convite à reflexão dirigido àqueles educadores que também desconfiam que "há algo de errado com o mundo" ${ }^{3}$ - escolar -, sobretudo em sua dimensão cotidiana da sala de aula.

Vamos iniciar nossa viagem. Ela começa no nosso cotidiano - o mais comum de nossos lugares sociais; onde estamos tão à vontade que não sabemos, nem precisamos saber por que estamos ali. No cotidiano agimos como sonâmbulos; não sabemos, ao certo, se estamos dormindo ou acordados e, por vezes, parece não fazer muita diferença. Nosso "sono" cotidiano se estende de nossas camas para as ruas, das ruas para o trabalho, do trabalho para as pessoas - tão as mesmas todos os dias - até que acordamos quando alguém nos chama pelo nome. Nomeianos entre muitos, no meio da multidão, somos chamados a despertar.

No filme, Thomas Anderson e seu duplo "Neo" alternam-se em aparições no sono um do outro: o primeiro, respeitável programador de uma grande empresa de softwares, mas que parece não se encaixar em seu mundo. Ao chegar atrasado novamente ao emprego, é chamado a respeitar o corpo de funcionários de sua empresa de forma a não romper-lhe o equilíbrio interno. Esse equilíbrio é dado pelo seguimento cego, diga-se - das regras da instituição. Isso nos leva a suspeitar da crescente insatisfação que vai tomando conta do programador: um trabalhador criativo, assim o exige sua função, que vai sentindo-se encarcerado pelo mundo das regras e, ironicamente, pelas máquinas que ele próprio põe a funcionar. O homem que busca um outro "eu", uma existência, pois o sistema de produção que emergiu renovado da Revolução Industrial foi instalando-se e alargando-se na mesma proporção que o sujeito foi encolhendo-se, foi sendo obrigado a se esconder, a se camuflar sob as dobras da economia e das necessidades macro-sociais que a produção the foi impondo. Esse movimento, historicamente, nos informa Foucault (1999, p. 425), é o próprio movimento do surgimento do homem: "Antes do fim do século XVIII, o homem não existia. Não mais que a potência da vida, a fecundidade do trabalho ou a espessura histórica da linguagem. É uma criatura muito recente que a demiurgia do saber fabricou com suas mãos há menos de 200 anos (...)”.

A busca de um outro, de um duplo, inscreve-se na direção da possibilidade de existência do outro. Caso contrário, há algo de errado 
com o mundo. Resta inquirir de nós para nós mesmos: Quem fabricou esse outro "eu"?

Ambos, o programador e o hacker, se sabem iguais no mesmo corpo e distintos diante da sociedade que os criou. $\mathrm{O}$ primeiro é um retrato em negativo do segundo e vice-versa. $\mathrm{O}$ que nos permite dizer que eles são $o$ mesmo no outro.

O hacker é aquele que trafica informaçōes sigilosas e vive num mundo fantástico de programações de computadores, talvez como forma de dizer a si mesmo que não segue regras, ao menos não aquelas oriundas do mundo do programador. Burla-as, corrompe-as, supera-as, mas, no mesmo movimento, entrega-se a novas regras. Ao traficar as informações avisa: "se você for pego com isto, você não me conhece". ${ }^{4}$ Dupla insatisfação: nega-se as regras do mundo, mas, ao fazê-lo, fundamenta-se em novas regras. Assim funcionam as formaçōes discursivas que Foucault (1997) analisa: só se pode romper com uma dada formação discursiva utilizando-se as ferramentas oferecidas por uma nova formação discursiva.

Ambos dominam seu espaço, ambos são rejeitados pela sociedade do outro, ambos estão em busca de alguém que lhes diga o sentido da vida. Assim sendo, ambos buscam alguém que também realiza uma busca. Talvez estejamos à procura daquele que desejamos ser, num sentimento de estranhamento de nós mesmos pelo que somos e fazemos em comparação com o que desejaríamos ser e fazer, mas que teimosamente se esconde por detrás daqueles que nos permitem ser, ao menos por enquanto! Daí o forte apelo que nos faz o lema de Píndaro - Chega a ser o que és! -, repetido por Nietzsche no Ecce Homo (2001) e retomado por Larrosa (1999), apontando quão paradoxal é ser o que somos e o que desejamos ser. Desde Rousseau, segundo Larrosa (1999), a autobiografia moderna pode ser (re)inserida na formação, na bildungsroman - na novela de formação - do "Eu". Assim, Rousseau (1959, p. 11), o filósofo iluminista, abre suas Confissóes: "Dou começo a uma empresa de que não há exemplos, e cuja execução não terá imitadores. Quero mostrar aos meus semelhantes um homem em toda a verdade da natureza; e serei eu esse homem".

O presente texto se inscreve nas formas perscrutativas da formação do "Eu" no âmbito da trajetória de sua constituição no intramuros escolar. Direcionamos nosso foco para as possibilidades reflexivas a partir do filme The Matrix, pois ali vemos delinear-se uma busca intensa. 
Uma busca pelo significado da vida, da mesma vida que vivemos, demarcada pelo trabalho, pelo lazer, pela solidão, pelo sem-número de vezes que nos sentimos perdidos, inconformados, pois os sentidos que nos apresentam para viver parecem não ser suficientes, sufocam-nos. Incomodados pela razão do controle que sobre nós e sobre cada um exercem as instituições, máquinas sociais, os poderes constituídos, como um outro do qual não podemos nos livrar totalmente, nos forçam na direção daquilo que não desejamos ou, quando muito, quando parece ser o que desejamos, somos surpreendidos por algo que está na base dos nossos próprios desejos: o material com o qual eles são fabricados parece ser fornecido por alguém, com determinadas intençôes. Sempre que o tentamos, eles nos convocam para sua realidade.

Comumente somos chamados à realidade. Será que estamos acordados ou sonhando? Vamos nos deter, por um momento, nas formas de comunicação às quais somos submetidos e das quais não podemos escapar. Vivemos numa sociedade em que não precisamos mais procurar os meios de comunicação, eles nos encontram; somos todos localizáveis. Quem nos procura? Morpheu, o deus dos sonhos, filho do sono (Bulfinch, 2005). Ele nos diz: "Eles o procuram; faça o que eu disser". Assim são os deuses, põem e dispõem sobre nossas vidas, sempre que o permitimos: ordenam nossos menores atos. Estamos todos à disposição, mesmo não estando dispostos. Levam-nos a encarar os precipícios do cotidiano, ao menos, quando a eles nos submetemos!

Ao realizar essa busca pelo que somos, interrogamos pessoas, perscrutamos olhares, reviramos páginas e páginas que estão dispostas à nossa frente. Livros, jornais, revistas, impressos em geral, telas da tevê. Quando estamos andando pela rua e passamos diante da vitrine de uma loja na qual são vendidos televisores, estes aparecem diante de nós, todos ligados, como que dirigidos a nós, ligados por nossa causa, transformando aquela vitrine, que tem ao fundo uma parede, antes morta, em algo vivo, falante, que se dirige a nós. Nas telas do computador onde escrevemos e onde surgem coisas que não produzimos mas que se dirigem a nós independente de nossa vontade. Toda essa profusão do mundo letrado também nos interroga. O que querem saber de nós?

Quantas coisas nos interrogam durante um dia? Ao nos interrogarem, nos observam, nos expõem. Nossas entranhas são expostas sobre a mesa de trabalho de nossos observadores: "nós o temos observado; você 
tem duas vidas; uma tem futuro, a outra não", diz o agente Smith para Neo, no momento em que este foi capturado. Comunicar também pode significar capturar o outro. Podemos dizer que uma das melhores formas de capturar alguém, num processo dialógico, é dizermos que sabemos muito sobre esse alguém. O que ele é está em nossas mãos, de certa forma. Essas informações formam uma espécie de dossiê sobre quem somos. Eles sempre têm um dossiê sobre nós: nossas informações estão sendo compiladas por alguém, em algum lugar. A qualquer momento, elas podem ser usadas contra nós mesmos. $\mathrm{O}$ observar sobre nós tem um caráter de vigilância: o que fazemos, o que pensamos, aonde vamos, com quem nos relacionamos, quem procuramos... Diante deles e seu dossiê sobre nós perdemos a voz e até a boca. Falar o quê? Para quem? Esse diálogo que se estabelece entre eles e nós ultrapassa todos os limites do imaginável. Atravessa mesmo as fronteiras de nossa intimidade. Atravessa nossa pele. É um diálogo entranhado por nós.

No filme, podemos dizer que essa reflexão está associada à seqüência de cenas nas quais Neo é levado para uma sala de interrogatório, onde, após negar-se a colaborar com seus inquisidores, é submetido pela força a admitir um equipamento de transmissão que lhe é introduzido pelo umbigo a dentro. É um grampo, é uma escuta interna, é uma câmera que busca informar quem ele é por dentro de suas entranhas. Que idéias ou coisas eles colocam dentro de nós que lhes permitem saber tudo sobre nós, de dentro para fora? Seriam eles "fabricantes" de um habitus5? Como internalizamos o "olho do poder"? Foucault (1998, p. 211) nos adverte que a visibilidade do sujeito o posiciona nas relaçôes de poder que se estabelecem entre o observador e o observado: "a existência de um ponto central que deve ser o local de exercício do poder e, ao mesmo tempo, o lugar de registro do saber". Embora o autor esteja referindo-se ao panopticon de Jeremy Bentham, como um projeto arquitetônico para controle pleno do sujeito, seja ele um operário, um condenado, um paciente ou um estudante, podemos dizer que o exercício permanente dessa vigilância faz com que passemos da condição de vítimas, apenas, para a condição de cúmplices, já que a realizamos de dentro para fora.

Nós os levamos conosco onde formos! Agora as informações a nosso respeito estão vindo de nosso eu (ou "eus") interior(es). É um pesadelo viver no meio deles. Desejamos acordar e ver que era só um sonho. Mas nos perguntam: Acordar de quê? Acordar para quê? Por 
que estamos aqui? Por que não sabemos explicar o que sabemos, mas sabemos que sabemos, sentimos? Que valor tem os saberes oriundos de nossos sentidos ou, ainda, de nossas conjecturas? Quem são eles? A Matrix? Onde ela está? É a mesma pergunta que o peixe faz em relação ao oceano: Onde ele está? Mas quando o peixe se encontra nele pode senti-lo! Como tomar distância para ver a verdade que dizem a nosso respeito? Os sentidos, às vezes, nos traem, negam-nos o conhecimento. $\mathrm{O}$ conhecimento sobre quem somos. Isso pode ser extraído da cena em que Neo, após ter tomado a pílula vermelha (voltaremos a esse tema mais adiante), aquela que, segundo Morpheus, "o levará ao fundo da toca do coelho", está sendo "plugado". Ao olhar para o espelho fraturado que está próximo, num momento se vê também fraturado, seu rosto não pode ser reconhecido, mas tudo se desmancha, devolvendo-lhe seu rosto, mas este já é um novo rosto. Só há um jeito de sabê-lo: tocando-o.

Tocar o novo rosto supõe riscos e estes são parte integrante das escolhas que, diariamente, somos instados a fazer. São tantas escolhas que se nos apresentam no nosso cotidiano que, muitas vezes, não percebemos que elas já foram escolhidas antes para que as escolhêssemos depois. Toda escolha, em geral, coloca-nos diante de possibilidades de respostas às perguntas que nos fazemos e que nos impulsionam a fazê-las.

A resposta ou, melhor dizendo, as respostas a essas indagações supõem que façamos escolhas. São elas que nos levam aos portos, nem sempre tão seguros quanto desejávamos, mas que buscamos pela vida. Devemos nos dirigir nas nossas escolhas. Duas possibilidades nos são oferecidas, em caráter dicotômico: ou isso, ou aquilo, como no filme: ou a pílula azul, ou a vermelha. A pílula azul pode ser confundida com aquelas crenças que nos arrastam a fazer o que é esperado que façamos: dormir enquanto a realidade é construída ao nosso redor para que tudo esteja em seu devido lugar, de tal forma que não vamos sequer precisar inquirir se as coisas estão bem como estão. Nossos olhos acabam embotados pela realidade. Por que não tomá-la e acabar logo com esse pesadelo? Há escolhas que só se apresentam em nossas vidas uma vez. A quantos de nós já foi oferecida a possibilidade tentadora de conhecer o país das maravilhas: lá onde todos os nossos sonhos de consumo serão realizados de forma mágica...! Mas, toda escolha comporta perdas e ganhos. Quais serão os ganhos? Até onde vão as perdas? Como Alice, no país das maravilhas, somos convocados a nos perguntar: Onde termina a toca do coelho? Um desejo íntimo nos assalta, esgueirando-se 
por entre nossas mais sinceras intenções. Um desejo que nos seduz: "ah! O que custa, eu dou só uma olhadinha no fundo da toca e depois volto à minha vida normal...!".

Alice, no conto de Lewis Carrol, logo se depara com a rainha do lugar. A estranha e a realeza. Aquela que nada sabe e aquela que tudo pode, frente a frente. $\mathrm{O}$ país das maravilhas começa ou termina nas relações de poder. Talvez, por isso, possamos compreender que a trajetória iniciada por Neo ao tomar a pílula vermelha desemboca numa sala de comando. Metáfora do poder: para ter tudo o que mais se deseja na vida, há que se passar pelas relações de comando, de controle sobre os outros. É o que nos informam as relações de produção da sociedade capitalista. Trata-se de aceitar o inevitável, segundo essa lógica.

Por que a porta de passagem para esse mundo maravilhoso é o espelho? Onde chegaremos quando entrarmos por ele ou quando ele invade pelo nosso interior, espelhando tudo por onde passa, órgãos, tecidos internos, as paredes de um eu interior: há tantas paredes! Quando nasceria o "eu" definitivo? De volta ao lema de Píndaro, vamos fazer uma pequena alteração na forma original: “Chega, seja o que és!”. Essa é a novidade. O novo é como um nascimento: uma revolução para a humanidade, pois a partir dele tudo pode acontecer.

O nascimento de um bebê, mais um entre os mais de seis bilhões que a Terra possui. A máquina que os produziu, denominada mundo bumano, festeja. Nós, à volta do bebê, também festejamos, deixando para depois pensarmos a que ele veio, a quem ele veio, afinal, ele será mais um na árdua tarefa de construir esse mundo. Construção mediada pelo trabalho, numa sociedade que está ficando mais complexa a cada dia. Hannah Arendt (1997) nos auxilia a compreender melhor essa questão:

O último estágio de uma sociedade de operários, que é a sociedade de detentores de emprego, requer de seus membros um funcionamento puramente automático, como se a vida individual realmente houvesse sido afogada no processo vital da espécie, e a única decisão ativa exigida do indivíduo fosse deixar-se levar, por assim dizer, abandonar a sua individualidade, as dores e as penas de viver ainda sentidas individualmente, e aquiescer num tipo funcional de conduta entorpecida e "tranqüilizada". (Arendt, 1997, p. 335. Grifos nossos)

Talvez aquela máquina esteja cultivando seres humanos para sua própria sustentação, talvez ela possa ser chamada de "sistema de 
produção", a máquina da fome, a máquina do consumo desenfreado, a máquina dos saberes (médicos, escolares, acadêmicos e tantos outros). Bem-vindo ao mundo real! "Bem-vindo ao deserto da realidade", diz Morpheus.

"Meus olhos doem" de tanta realidade difusa, mas é assim mesmo: nós não estamos acostumados a olhar as várias realidades. Quando olhamos não vemos, quando vemos negamos. Por que olhamos? Para que olhamos? Para desviar o olhar sobre nós mesmos, pois quando nos olhamos corremos o risco de não nos reconhecermos... "Onde estou?" "Não importa saber onde, mas quando", 7 estou num tempo chamado agora que acaba de se tornar passado; o agora, o presente, é tão fluído que mal o denominamos e ele já está no passado. $\mathrm{O}$ ontem está presente nos nossos museus, mausoléus, edifícios, cemitérios, igrejas, álbuns de família, e está no mais impressionante edifício: o self: A diferença é que neste está o passado, o agora fluído e o futuro que já começa a se anunciar e ao mesmo tempo desintegrar. Essa impressão exala do filme o tempo todo. Parece que, de repente, está tudo ruindo ao nosso redor. "Esta é minha nave”: meu corpo! Dizer que ela é minha é só um eufemismo, pois a uso, provisoriamente, para me levar a algum lugar que desconheço.

Esta nave que carrega o self pode ser Nabucodonosor, o mensageiro da morte, nos escritos antigos e sagrados, responsável por ceifar a vida a tantos, pode ser agora o veículo que carrega justamente a esperança contra o extermínio total. Ironia do destino? Talvez. Assim o metaforiza o filme.

Mera coincidência. Um exterminador. Uma máquina de destruição. Afinal, Hitler não foi o primeiro e, provavelmente, não será o último. Matrix é controle, controle é real, real é ideal. Ao menos essa é a lógica da sociedade de classes em que vivemos. Esse é o branco luscofusco que nos envolve a todos numa cegueira que contagia, como já o indiciara Saramago (1999). Essa brancura-cega nos envolve a todos, como todos os programas de computador aos quais estamos submetidos: bancos, rede elétrica, fichas escolares eletrônicas, lista telefônica, as teorias desenvolvidas na escola e nos centros de pesquisa... Fomos reduzidos a um símbolo dentro de um grande banco de dados. A pergunta não é mais "qual é o seu número?", mas "qual é o seu código de acesso?".

"Bem-vindo ao deserto da realidade"!

$\mathrm{Na}$ realidade em que as máquinas imperam, ou naquela em que o pensamento mecanicista impera, uma nova humanidade está em 
gestação, como já o propõe Pretto (2000), a inteligência é artificial (IA) e artificial é nossa existência: o consumo, transformado em consumismo na sociedade capitalista, reduz a todos, indistintamente, ao mais baixo e ao pior de nós mesmos: o reverso do sentido; a (quase) plena falta de sentido; a condição que já não é mais humana. Somos todos cultivados por um sistema amplo que ninguém controla por inteiro.

Assim reduzidos ao sem-sentido, vivemos à espera de que algo mude, para que a vida possa ser, de novo, vivida com prazer. Enquanto isso, vivemos à espera: do ônibus, do emprego, do retorno da pessoa amada, daquela pessoa que ainda não temos, do filho que vai chegar, de algum herói que virá nos salvar. A espera gera a esperança que, se demandada em demasia, torna-se desesperança e pode virar desespero. Cabe a nós não permitirmos que o ciclo se feche. Não há tempo a perder: é preciso viver como humanos o que nos resta; resistir à desumanização plena. Resgatar o humano em cada um, em cada outro. A morte do outro é a morte do self que se constitui a partir do outro, num jogo de relaçôes que mais parece uma teia; somos tecelão e tecido a trabalhar em nosso ofício de nos tornamos naquilo que desejamos ser enquanto ainda não o somos. Os fios de nossa história se entretecem nos fios das histórias de cada um; somos uma mescla de histórias de vida; somos um mosaico: ricos e pobres, negros, abandonados, esbeltos, portadores de deficiências, umas visíveis, outras não, mas todas produzindo os seus desdobramentos.

$\mathrm{O}$ que dizer da escola nesse universo de conexões que vai se estabelecendo como uma grande rede que a tudo e a todos envolve?

Talvez ela não passe de um mero setor da grande "Matrix", pois ela também participa, de alguma forma, sobretudo, a partir de determinados sujeitos, de um organismo que cultiva seres humanos. Essa metáfora aparece no filme em que, no maravilhoso sonho que a realidade representa para todos nós, estão as inovações tecnológicas sempre a nos atrair, a nos encantar, a nos convencer. Morpheu informa a Neo: "Há campos, Neo. Campos sem fim. Nos quais os humanos não nascem mais, são 'cultivados"”. ${ }^{8}$ Cultivados para estarem a serviço dos interesses dos grandes aparatos sistêmicos que elaboram tudo o que esses corpos, quase inertes, dos humanos precisam. Não é demais lembrarmos que Adorno e Horkheimer tinham lá suas razões ao apresentarem as formas de comunicação articuladas como indústria cultural. Produz-se 
cultura e a cultura (re)produz os seres humanos. Podemos dizer que eles se inscreveram, naquele momento, como precursores da análise de uma sociedade que seria brilhantemente exposta no filme The Matrix.

Cultivar seres humanos é algo que se aproxima do trabalho pedagógico. O que fazemos quando ensinamos nossos alunos? Mera metáfora do controle realizado pela instituição escolar, poder-se-ia dizer, apressadamente. Porém, convém irmos mais além. A escola vista como aparelho ideológico do Estado, conforme o propôs Althusser (2001), ou como aquela que reproduz a sociedade, na análise que aparece em $A$ reprodução, de Bourdieu e Passeron (1975), cumpre seu papel no interior de um grande paradoxo: ao mesmo tempo em que nos controla e nos ensina a importância de sermos controlados, também permite compreender o funcionamento da ideologia dominante e seu corolário no processo de produção econômica e de reprodução de um "Eu" submisso e assujeitado, o que poderia nos levar a ensejar as transformaçōes que libertariam a todos. No filme, Morpheu informa a Neo que isso supõe um grande risco: aqueles que necessitam de liberdade são cúmplices do sistema que os criou.

Hoje, necessitando compreender o papel exercido pelas diferentes formas de resistência, desconfiamos que a institucionalização do sujeito no ambiente escolar é um fenômeno que se reduplica na sua própria negação. $\mathrm{Na}$ mesma medida em que somos submetidos a um processo que retira os sentidos de nossas vidas e a ela atribui novos, abrem-se as possibilidades de nos transformarmos e transformamos as relações sociais que nos envolvem. Se, como dissemos no início deste trabalho, uma nova forma de relação entre seres humanos e máquinas está em curso, é inevitável que uma nova instituição também esteja sendo forjada nesse processo. No filme The Matrix, o agente Smith (funcionário da Matrix) tenta eliminar Neo e, segurando-o diante de um trem que se aproxima, o informa sobre a condição que o destino nos impóe: a inevitabilidade da vida e seu duplo, a morte, define nossa passagem por este plano de existência. ${ }^{9}$

Na metáfora da "Matrix" trazida pelo filme, o pensar, os gostos, os desejos, a realidade, tudo não passa de um produto daquele que construiu o sistema de controle. Assim, podemos dizer que, na medida em que a escola atua no "desvelamento" da realidade diante de seus alunos, ideologicamente recria o "velamento" sobre suas formas de controle do pensamento. Inevitabilidade. Resistência. Transformação. Temperos com 
os quais o sistema de produção cria o alimento mais comum do nosso cotidiano: nossa cosmovisão. E é exatamente com ela que olhamos ao nosso redor e desconfiamos, como Neo: há algo errado com o mundo.

A "Matrix" informa aos seres humanos o sabor de alimentos, a textura da matéria que tocam, a temperatura que pode ser sentida, enfim, todas as sensações humanas controladas por um "eu" exterior, excêntrico, devorador de energia humana. A estratégia parece bastante eficaz: não se trata de apresentar novos conceitos, mas de oferecer uma nova ferramenta de produzir conceitos. O controle é melhor exercido quando realizado de dentro para fora do sujeito. "Sorria, você está sendo filmado!", proposta do novo panopticon ${ }^{10}$ : "A moral reformada; a saúde preservada; a indústria revigorada; a instrução difundida; os encargos públicos aliviados; a economia assentada, como deve ser, sobre uma rocha; o nó górdio da Lei sobre os Pobres não cortado, mas desfeito - tudo por uma simples idéia de arquitetura!" (Bentham, 2000, p. 15).

No filme, a introdução de um organismo de vigilância, um "grampo" no corpo de Neo, realizado pelo agente Smith e seus homens-máquina, insere-se na mesma proposta da visibilidade do interior do "Eu", capturando o que lhe é mais íntimo: seus desejos, sua vontade, até mesmo sua visão de mundo, como já enunciamos acima.

Nesse sentido, podemos dizer que a escola, uma espécie de Matrix da modernidade, vai produzindo nos campos férteis da alma humana mais do que apenas submissão, mas a própria vontade.

Vamos voltar à velha crítica de que a escola reproduz o sistema? Não, exatamente! Que haja reprodução do sistema, inclusive na escola, não demanda mais discussão. O que tratamos aqui é de outra coisa: acordaremos desse sono/sonho mitológico ao qual o capitalismo nos submeteu? A escola pode apontar a porta para que ultrapassemos os limites atuais aos quais estamos aprisionados? No filme, indicia-se uma saída: o oráculo. Façamos, em tempo, uma correção: o oráculo não é a saída, mas sabe onde ela está e pode indicá-la. Mas, ouvir o oráculo não é para qualquer um. É preciso estar atento o suficiente e disposto a enfrentar as charadas que muitas vezes cobrem a palavra salvadora. $\mathrm{O}$ oráculo é também uma forma discursiva. Esta, por sua vez, está inserida numa formação discursiva.

O primeiro filme da trilogia Matrix termina com o homem rehumanizado para além das possibilidades imaginadas para ele durante seu percurso na vida. Na última cena, Neo aparece diante de um telefone, 
quando um aviso, uma advertência, surge avassaladora: "não vim para dizer como tudo isso vai terminar, mas como vai começar”. Ele já não é mais o mesmo. Nem cada um de nós, ao vivermos a experiência da formação escolar. Percebemos os abismos como o propôs Nietzsche (2001, p. 27): "O homem é corda estendida entre o animal e o Super-homem: uma corda sobre um abismo; perigosa travessia (...)”. Eis o ponto de chegada: um salto de um lado para o outro que pressupóe os maiores e piores riscos quando nos dispomos a não mais ser controlados e manipulados. Surge o super-homem nietzscheano: aquele capaz de superar-se a si próprio, a seus próprios medos e limites. Aquele que deseja realizar a travessia e não perpetuar-se na cômoda esfera do já-pensado-para-si, mas aquele que deseja romper com as amarras de uma vida que não desejou e de uma realidade da qual não foi partícipe em sua gênese e construção. Um desejo profundo de assumir as rédeas da própria vida, como o propôs Larrosa (1999) a partir de Rousseau, e passar a dizer, antes a si próprio, quem se é, o que quer da vida e o que entende por formação.

Para encerrarmos e para dizer que algo se espera por consolo, podemos afirmar que essa transformação poderá ocorrer na vida de cada um de nós de duas formas: nos atiramos na direção das grandes apostas e escolhas que vislumbramos no decorrer de nossas vidas ou as circunstâncias, ao nosso redor, nos jogarão para o seio de mudanças que não escolhemos. Aparentemente, é uma escolha como aquela apresentada no filme: ou a pílula azul da aceitação do inevitável, ou a pílula vermelha do novo, do risco, da toca do coelho, que não se sabe onde exatamente vai terminar.

Recebido em setembro de 2006 e aprovado em agosto de 2007.

\section{Notas}

1. De acordo com a Teoria Alegórica, indicada por Bulfinch (2005, p. 353), Cronos, pai de Zeus, era aquele que devorava os próprios filhos.

2. Segundo Bárbara Theoto Lambert, tradutora do texto de Alice no país das maravilhas (Carroll, 2002), Lewis Carroll não era o nome legítimo do autor do conto, Charles Dodgson, um professor de matemática de Oxford. Fotógrafo que, além de tirar inúmeras fotos da família do coordenador religioso de "Christ Church" e da filha daquela família, Alice Pleasance Liddel, dedicou a esta o conto.

3. Frase do Filme The Matrix proferida por Morpheus no diálogo inicial que trava com Neo.

4. Frase do Filme The Matrix proferida por Neo no momento em que entrega o disco com informações ao personagem denominado Choi. 
The Matrix: a aventura da formação no mundo tecnologizado

5. Pierre Bourdieu destaca, em seu livro $O$ poder simbólico, a filiação aristotélica do conceito habitus, oriunda de hexis. A conversão deste para aquele foi realizada pela escolástica. Bourdieu considera o habitus como um conhecimento adquirido, uma espécie de "haver", um "capital", enfim, uma disposição que, para além do "hábito", coloca o sujeito em estado de disposição, preparado (Bourdieu, 1989, p. 61).

6. Frase do filme The Matrix proferida por Neo ao acordar após sua acolhida na nave Nabucodonosor.

7. Diálogo entre Neo e Morpheus, após seu restabelecimento a partir do processo de reconstrução de seu corpo pela equipe da nave Nabucodonosor.

8. Frase do filme The Matrix proferida por Morpheus no momento em que está revelando a Neo o que é "Matrix". Ao fazê-lo, apresenta a imagem de campos nos quais os seres humanos são cultivados pelas máquinas para satisfazer sua necessidade de energia.

9. Após forte luta entre Neo e Smith, este, com uma "gravata", o segura enquanto se aproxima o trem do metrô. No momento em que o atropelamento parece inevitável, Neo consegue dar um salto, livrar-se de seu oponente, deixando-o impossibilitado de escapar. A inevitabilidade foi mantida, porém refeita, invertida.

10. A construção que a modernidade nos legou como herança. Pensada inicialmente para um presídio, rapidamente, mostrou-se eficaz em outros setores da vida humana: hospitais, manicômios, fábricas, escolas.

\section{Referências bibliográficas}

ALTHUSSER, L. Aparelhos ideológicos do Estado: notas sobre os aparelhos ideológicos do Estado. 8. ed. Trad. de Walter José Evangelista e Maria Laura Viveiros de Castro. Rio de Janeiro: Graal, 2001.

BENTHAM, J. O panóptico ou a casa de inspeção. Trad. e org. de Tomaz Tadeu da Silva. Belo Horizonte: Autêntica, 2000.

BOURDIEU, P. O poder simbólico. Trad. de Fernando Tomaz. Lisboa: DIFEL; Rio de Janeiro: Bertrand, 1989.

BOURDIEU, P.; PASSERON, J.C. A reprodução: elementos para uma teoria do sistema de ensino. Rio de Janeiro: Francisco Alves, 1975.

BULFINCH, T. O livro de ouro da mitologia (a idade das fábulas): histórias de deuses e heróis. Trad. de David Jardim Júnior. 32. ed. Rio de Janeiro: EDIOURO, 2005.

CARROLL, L. Alice no pais das maravilhas. Trad. de Bárbara Theoto Lambert. São Paulo: Loyola, 2002.

EAGLETON, T. Ideologia. Trad. de Silvana Vieira e Luis Carlos Borges. São Paulo: UNESP; Boitempo, 1997. 
FOUCAULT, M. Vigiar e punir. Trad. e org. de Roberto Machado. Rio de Janeiro: Graal, 1996.

FOUCAULT, M. Arqueologia do saber. Trad. de Luis Felipe Baeta Neves. 5. ed. Rio de Janeiro: Forense Universitária, 1997.

FOUCAULT, M. Microfisica do poder. Trad. e org. de Roberto Machado. Rio de Janeiro: Graal, 1998.

FOUCAUlT, M. A ordem do discurso; aula inaugural no Collège de France, pronunciada em 2 de dezembro de 1970. Trad. de Laura Fraga de Almeida Sampaio. 4. ed. São Paulo: Loyola, 1998.

FOUCAULT, M. A verdade e as formas jurídicas. Trad. de Roberto Cabral de Melo Machado e Eduardo Jardim Morais. Rio de Janeiro: Nau, 1999.

GINZBURG, C. Mitos, emblemas e sinais. Tradução de Federico Carotti. São Paulo: Cia das Letras, 1999.

KUENZER, A.Z. Educação, linguagens e tecnologias: as mudanças no mundo do trabalho e as relações entre conhecimento e método. In: Candau, V. (Org.). Cultura, linguagem e subjetividade no ensinar e aprender. Rio de Janeiro: DP\&A, 2000. p. 135-160.

LARROSA, J. Pedagogia profana: danças, piruetas e mascaradas. Belo Horizonte: Autêntica, 1999.

NIETZSCHE, F. Assim falou Zaratustra. São Paulo: Martin Claret, 2001.

NIETZSCHE, F. Ecce homo: como cheguei a ser o que sou. São Paulo: Martin Claret, 2001.

PRETTO, N.L. Linguagens e tecnologia na educação. In: CANDAU, V. (Org.). Cultura, linguagem e subjetividade no ensinar e aprender. Rio de Janeiro: DP\&A, 2000. p. 161-182.

SAMARAGO, J. Ensaio sobre a cegueira. São Paulo: Cia das Letras, 1995. ROUSSEAU, J.J. As confissóes. São Paulo: Atena, 1959. 